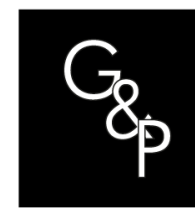

\title{
Phases and tools for supply chain risk management: a systematic literature review
}

\author{
Fases e ferramentas para gestão de risco na cadeia de \\ suprimentos: uma revisão sistemática da literatura
}

\author{
Priscila Gomes Pereira Gaspar ${ }^{1}$, Paula Santos Ceryno ${ }^{2}$ (), Ana Luiza Ferrer ${ }^{1}$, \\ Antônio Márcio Tavares Thomé ${ }^{1}$ (1) \\ ${ }^{1}$ Pontifícia Universidade Católica do Rio de Janeiro - PUC-Rio, Departamento de Engenharia Industrial, Rio de \\ Janeiro, RJ, Brasil. E-mail: priscilagaspar@hotmail.com; analcferrer@gmail.com; mt@puc-rio.br \\ ${ }^{2}$ Pontifícia Universidade Católica do Rio de Janeiro - PUC-Rio, Departamento de Engenharia de Produção, Rio de \\ Janeiro, RJ, Brasil. E-mail: paula.ceryno@unirio.br
}

How to cite: Gaspar, P. G. P., Ceryno, P. S., Ferrer, A. L., \& Thomé, A. M. T. (2020). Phases and tools for supply chain risk management: a systematic literature review. Gestão \& Produção, 27(3), e4227. https://doi.org/10.1590/0104-530X4227-20

\begin{abstract}
Supply chain risk management (SCRM) has been widely discussed in the academic literature and several models have been proposed in recent years, but there is a need for a model encompassing phases and tools for SCRM. This study presents a systematic literature review (SLR) of 254 abstracts and 68 full-text papers. The SLR made it possible to identify and define the main phases for the SCRM, as well as the tools proposed for each phase. There is a concentration of efforts in the phases of identification, assessment, and selection of risk management strategies and a limited number of studies in monitoring and controlling risks. The article offers a global SCRM framework, contributing to the theoretical discussions and a practical guide to implementation related to SCRM.
\end{abstract}

Keywords: Risk management; Supply chain; Supply chain risk management; Systematic review; Phases; Tools.

Resumo: O gerenciamento de riscos na cadeia de suprimentos (GRCS) tem sido amplamente discutido na literatura acadêmica e vários modelos foram propostos nos últimos anos, porém persiste a necessidade de um modelo que englobe fases e ferramentas. Este artigo apresenta uma revisão sistemática da literatura (RSL), onde 254 resumos foram analisados, e 68 artigos foram lidos na integra, visando a revisão completa de seus conteúdos. A RSL possibilitou a identificação e definição das principais fases para a GRCS, assim como as ferramentas propostas para cada fase. Há concentração dos esforços nas fases de identificação, avaliação e seleção das estratégias de tratamento dos riscos e um número limitado de estudos em monitoramento e controle de riscos. O artigo oferece um framework global de GRCS, contribuindo com as discussões teóricas relacionadas ao tema, além de fornecer um guia prático para sua implementação.

Palavras-chave: Gestão de risco; Cadeia de suprimentos; Gestão de riscos em cadeias de suprimentos; Revisão sistemática; Fases; Ferramentas.

Received Aug. 14, 2017 - Accepted Feb. 12, 2018

Financial support: Brazilian Coordination for the Improvement of Higher Education Personnel (CAPES) - Finance Code 001; National Council for Scientific and Technological Development (CNPq), Grant \# 304931/2016-0 and 404682/2016-2, and the Research Support Foundation of the State of Rio de Janeiro (FAPERJ), Grant \# E-26/203.252/2017. 


\section{Introduction}

The continuous growth of supply chain complexity increases its vulnerability to disturbances (Craighead et al., 2007; Sofyalığlu \& Kartal, 2012; Thun \& Hoenig, 2011), reinforcing the need to manage risks (Gredal et al., 2017; Heckmann et al., 2015; Tang \& Nurmaya Musa, 2011). There are numerous examples of disturbances in supply chains presented in the literature, such as the 9/11 terrorist attack (Jüttner, 2005), the Somali pirate attacks, Fukushima earthquake (Olcott \& Oliver, 2014), demand fluctuations, changes in supply capacity, lead time variability, exchange rates volatility, among others (Ceryno et al., 2015; Esmaeilikia et al., 2016).

As a result, these disturbances may cause an interruption in the flow of goods, services, money and/or information in the supply chain and consequently hinder its performance (Pfohl et al., 2010), justifying the reason for which supply chain risk management (SCRM) has become an important topic of study (Elleuch et al., 2014; Fahimnia et al., 2015; Hachicha \& Elmsalmi, 2014; Tang \& Nurmaya Musa, 2011; Thun \& Hoenig, 2011).

Despite the presence of a considerable amount of SCRM related academic literature (Cohen \& Kunreuther, 2007; Heckmann et al., 2015; Ho et al., 2015; Manuj \& Mentzer, 2008b; Olson \& Swenseth, 2014; Olson \& Wu, 2010; Pfohl et al., 2010; Simangunsong et al., 2012; Tang, 2006 a,b), the topic remains attractive and emerging, and the need to build frameworks for the subject persists (Fahimnia et al., 2015). Different frameworks for SCRM are present in the literature (Berle et al., 2011; Berle et al., 2013; Bradley, 2014; Cohen \& Kunreuther, 2007; Elleuch et al., 2014; Fazli et al., 2015; Ghadge et al., 2013; Giannakis \& Louis, 2011; Giannakis \& Papadopoulos, 2016; Hachicha \& Elmsalmi, 2014; Ho et al., 2015; Kern et al., 2012; Lavastre et al., 2014; Manuj \& Mentzer, 2008a; Micheli et al., 2014; Oehmen et al., 2009; Pradhan \& Routroy, 2014; Radivojević \& Gajović, 2014; Ritchie \& Brindley, 2007; Tummala \& Schoenherr, 2011). However, the need for a holistic approach regarding SCRM remains (Fan et al., 2016), which backfires on practical applications, once this gap also surfaces whenever the scarcity of holistic practical applications in SCRM is observed (König \& Spinler, 2016). There is equally a paucity of studies relating the phases of SCRM to the tools used in each phase.

This paper seeks to contribute to reducing the gap presented here, adopting an approach based on systematic literature review. A systematic review goes beyond the mere revision or compilation of previous studies. It consists of an objective, transparent and reproducible methodology to select, analyze and synthesize data that answer specific research questions, allowing for the clear identification of what is known or unknown of a given subject (Denyer and Tranfield, 2009, p. 671). It follows strict and pre-established protocols for document revision, offering a clear track so that obtained results are audited in a scientific manner (Tranfield et al., 2003). It has been adopted in various fields, such as medicine (Higgins \& Green, 2008), social sciences (Campbell Collaboration, 2014), management (Denyer \& Tranfield, 2009) and increasingly in the areas of operations management and industrial engineering (Thomé et al., 2016). For Torraco (2005), systematic reviews function to provide a classification or taxonomy of topics of interest of a given subject, present and describe the relationship between these topics through conceptual frameworks. In addition, the reviews allow for the identification of breaches or less explored aspects, providing a research agenda. Finally, it allows for conceptual contributions through meta-theories or the combination of new approaches in existing theories. This paper offers a systematic literature review based on pre-established protocol, aiming to provide a typology, framework and 
research agenda on the tools used in the various phases of SCRM. This article seeks to answer two research questions: (i) what are the main phases suggested in the literature for SCRM and (ii) what are the main tools used for each phase. In this regard, the state of the art will be verified and analyzed with respect to SCRM frameworks and their main phases and tools. As a result, a global framework is proposed, relating the main tools to each phase with the purpose of facilitating the practice of risk management implementation in supply chains. This paper's main conceptual contribution consists of the elaboration of a practical guide for the selection of tools adapted to the different SCRM phases through a framework relating phases and tools and suggestions for future research on the subject.

\section{Methodology}

A systematic literature review was conducted based on Thomé et al. (2016) following eight steps: (i) planning and formulating the problem, (ii) searching the databases, (iii) data gathering, (iv) data quality evaluation, (v) data analysis, (vi) interpretation of results, (vii) presenting results, and (viii) updating previous reviews.

For the first step, the need for the systematic review was identified, the research team was constituted, and the review scope was defined, in accordance with recommendations from Cooper (1988), covering the aspects of focus, goal, perspective, coverage, and audience. The focus was in the methods and tools of SCRM, with the goal of identifying its central aspects, under a scientific perspective, representing the coverage of SCRM in operations management and industrial engineering, for a public of scholars and supply chain managers. In this step, the research protocol was equally established.

For the second step of the systematic approach, the databases were selected and keywords for the database queries were defined. Moreover, inclusion and exclusion criteria were established based on the inspection of titles and abstracts of selected documents, as well as the complete examination of articles used in the synthesis and data analysis steps. A search through the documents' citations and through articles that cited the selected documents completed the database document selection. During this process, agreement verifications were performed by at least two reviewers and discrepancies were analyzed with the participation of a third author.

The search and selection of documents were based on Thomé et al. $(2014,2012)$. The databases selected were EMERALD, SCIENCE DIRECT, SPRINGER, TAYLOR \& FRANCIS, and WILEY, because they concentrate the main publications on SCRM. For the sake of enriching the paper, grey literature was included in the literature review. For this purpose, searches were conducted in conferences relevant to the area (e.g., EUROMA, ENEGEP, POMS, and ANPET). Keywords used to perform searches in these databases were: (("SUPPLY CHAIN RISK" AND "FRAMEWORK") OR ("SUPPLY CHAIN RISK" AND "MODEL")). These keywords were adapted to each database's search engine. The search was concentrated on document title, abstract, and keywords, with no restrictions regarding publication dates. Selected keywords were comprehensive in order to avoid artificially limiting the search field and specific enough as to avoid undesirable results (Cooper, 2010; Thomé et al., 2014). In other words, the initial search words were defined as to balance what Petticrew \& Roberts (2006, p. 81) call sensitivity (attainment of all relevant documents) and specificity (disregard of irrelevant documents), which is consistent with the coverage sought in the scope of the review. 
The search returned 259 documents and all abstracts were examined by at least two authors. Before initiating the review process, exclusion criteria were defined (Cooper, 2010; Thomé et al., 2016). They were:

- Documents that do not analyze supply chain risk management;

- Documents that address supply chain risk management superficially, that is, it is not the paper's main subject.

Following the exclusion criteria, 157 documents were eliminated during the first round. A second round was executed in order to solve disagreements, that is, articles that were excluded by only one of the authors. Although the percentage of agreement based on Krippendorf's alpha (Krippendorff, 2004; Neuendorf, 2002) was considered satisfactory (87.8\%), all disagreements were discussed aiming to achieve $100 \%$ agreement. For this purpose, documents, where disagreements took place, were fully examined and during the second round, 15 of these articles were eliminated, following the same exclusion criteria from the first round. After the first and second round, 87 documents remained.

For the third step of the systematic review, following protocol specified in Thomé et al. (2016), data were collected in an analytical spreadsheet with the identified categories for the classification of phases and SCRM tools.

After all, 87 documents were fully examined, 17 were eliminated and the percentage of agreement between authors reached a Krippendorf's alpha of $92 \%$. Once again, disagreements were handled and two more documents were eliminated, thus leaving 68 documents in the sample.

Figure 1 presents document search and selection per database.

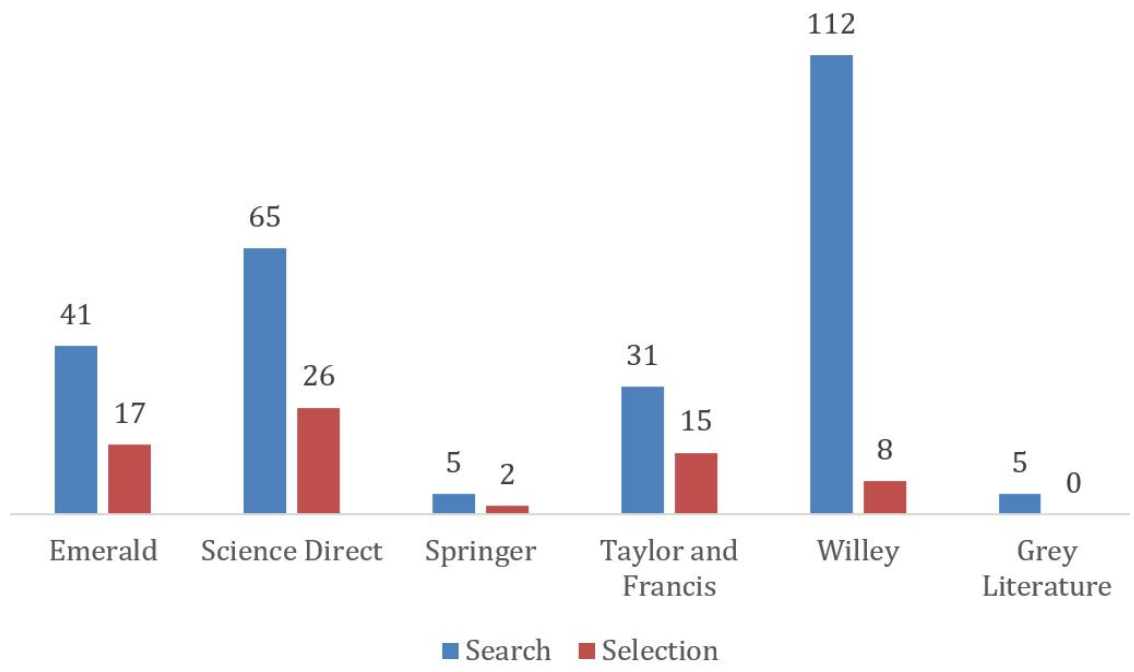

Figure 1. Document search and selection.

Figure 2 presents the distribution of selected documents throughout the years. 


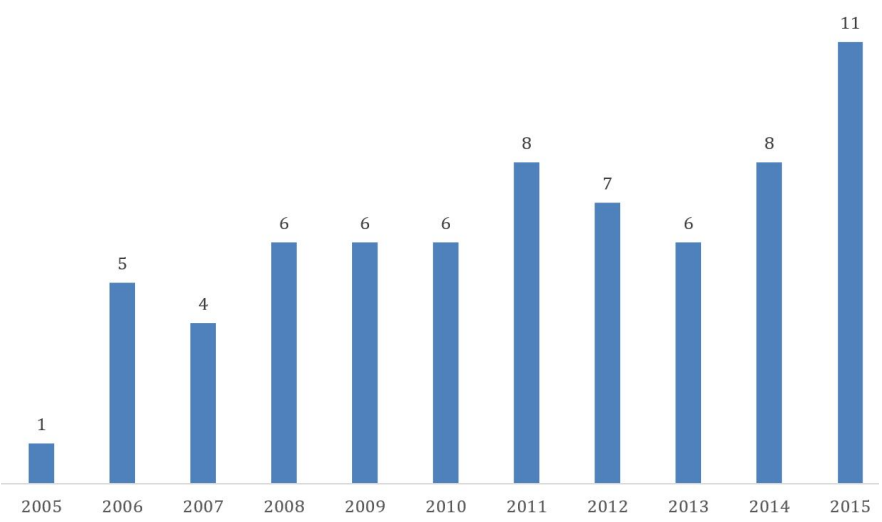

Figure 2. Selected articles distributed by year of publication.

The fourth step in the protocol consists of the evaluation of the quality of primary studies included in the analysis. Aiming to identify the quality of selected studies, the first author's $\mathrm{h}$-index was verified for documents with most citations, because this index considers the number of papers with citations $\leq \mathrm{h}$ and can be understood as the author's influence in his research field (Hirsch, 2005). According to Thomé et al. (2016), in order to identify key authors in a research subject, the number of publications must be supported by a measure of the impact of their publications, which is measured by the h-index in this article. Table 1 presents the number of articles published by these authors, the author's percentage of citations in relation to the total number of citations of the 68 documents in the sample and the author's h-index. Table 1 indicates the authors with up to $80 \%$ of the total number of citations in the sample, ordered by decreasing number of citations.

Table 1. Authors influence.

\begin{tabular}{cccc}
\hline Author & Number of documents & h-index & \% Citations \\
\hline Tang, C. & 99 & 27 & 16 \\
\hline Kleindorfer, P. & 100 & 25 & 15 \\
\hline Manuj, I. & 15 & 5 & 7 \\
\hline Gaudenzi, B. & 6 & 2 & 7 \\
\hline Wu, D. & 29 & 12 & 6 \\
\hline Faisal, M. & 24 & 11 & 4 \\
\hline Goh, M. & 121 & 19 & 3 \\
\hline You, F. & 144 & 29 & 3 \\
\hline Ritchie, B. & 13 & 6 & 3 \\
\hline Trkman, P. & 48 & 15 & 3 \\
\hline Schoenherr, T. & 53 & 17 & 3 \\
\hline Oke, A. & 25 & 12 & 2 \\
\hline Pfohl, H. & 14 & 6 & \\
\hline
\end{tabular}

Analyzing Table 1, it is possible to determine that a correlation between the number of publications and the influence factor exists, once in most cases authors with a high number of publications have a greater $h$-index.

Therefore, one may say the sample is representative of the researched subject, once the authors presented in Table 1 are widely cited and the $\mathrm{h}$-index has demonstrated their influence in the addressed research field. 
The data analysis and synthesis steps, corresponding to step 5 of the systematic review methodology, are presented in Section 3 (phases) and 4 (tools). Step 6 of the review protocol is presented in Section 5. This paper presents the results, consisting of step 7 of the systematic review methodology. Step 8 of the protocol, update of previous literature reviews on the same subject, is outside the scope of this study.

\section{Phases of supply chain risk management}

After analyzing all 68 articles, the seven phases of SCRM were listed and defined. They are context analysis, risk identification, risk evaluation, strategy selection for risk treatment, strategy implementation, control, and monitoring.

Context analysis consists of the definition of the issue to be managed. This analysis involves understanding what are the main actors of the supply chain, their roles and responsibilities, who is responsible for what, and what measures have already been implemented (Harland et al., 2003). Only actors that may potentially present substantial losses for themselves or another member of the chain or even yet the chain as a whole should be contemplated in the risk management process (Harland et al., 2003). From the context analysis, the scope of the risk management process can be developed, delimiting members that should be taken under consideration and their responsibilities within the supply chain (Cucchiella \& Gastaldi, 2006; Oehmen et al., 2009). Once the scope is defined, the next phase begins: risk identification.

During the risk identification, the risks to which the selected members of the chain are exposed to are identified. The risk identification phase is considered the main phase in the process of supply chain risk management by many authors (Aqlan \& Lam, 2015; Elleuch et al., 2014; Ghadge et al., 2013; Giannakis \& Papadopoulos, 2016; Hachicha \& Elmsalmi, 2014; Harland et al., 2003; Kern et al., 2012; Kleindorfer \& Saad, 2005; Oehmen et al., 2009; Pujawan \& Geraldin, 2009; Ritchie \& Brindley, 2007). The goal of this phase is to create a "profile" for each identified risk (Ghadge et al., 2013; Manuj \& Mentzer, 2008b). It is only after the risk identification that their respective consequences may be evaluated (Tummala \& Schoenherr, 2011).

The risk evaluation phase consists of estimating the risk event's occurrence probability and potential impacts and, therefore, prioritize risks that affect chain vulnerability (Elleuch et al., 2014; Ghadge et al., 2013; Giannakis \& Louis, 2011; Hachicha \& Elmsalmi, 2014; Harland et al., 2003; Ho et al., 2015; Kern et al., 2012; Kleindorfer \& Saad, 2005; Manuj \& Mentzer, 2008b; Oehmen et al., 2009; Ritchie \& Brindley, 2007; Tummala \& Schoenherr, 2011; Tuncel \& Alpan, 2010). This phase promotes an understanding of the relationship between identified risks (Giannakis \& Papadopoulos, 2016; Oehmen et al., 2009) and aims at evaluating and comprehending each risk in detail, taking their relevance into account (Aqlan \& Lam, 2015; Kern et al., 2012).

The selection of a risk mitigation strategy consists in evaluating various possible strategies in order to select the one that best suits each risk's treatment (Elleuch et al., 2014; Ghadge et al., 2013; Giannakis \& Louis, 2011; Kern et al., 2012; Kleindorfer \& Saad, 2005; Manuj \& Mentzer, 2008b; Oehmen et al., 2009; Pujawan \& Geraldin, 2009; Tummala \& Schoenherr, 2011; Tuncel \& Alpan, 2010). The strategy selection process must take into account the necessary costs for implementation. The selected strategy must bring benefits to the chain that justify its cost (Ghadge et al., 2013; Kleindorfer \& Saad, 2005; Oehmen et al., 2009; Tummala \& Schoenherr, 2011; Tuncel \& Alpan, 2010).

During the risk treatment strategy implementation phase, the selected strategy is implemented focusing on treating the previously prioritized risk (Elleuch et al., 2014; 
Ghadge et al., 2013; Giannakis \& Louis, 2011; Hachicha \& Elmsalmi, 2014; Harland et al., 2003; Kern et al., 2012; Kleindorfer \& Saad, 2005; Manuj et al., 2014; Oehmen et al., 2009; Pujawan \& Geraldin, 2009; Ritchie \& Brindley, 2007; Tummala \& Schoenherr, 2011). With regard to the final goal of this phase, one may verify the literature presents different focuses. The first focus indicates that this phase aims at reducing the consequences of the risk, in a relative view (Aqlan \& Lam, 2015; Manuj \& Mentzer, 2008b). The second focus stresses the elimination or reduction of the probabilities of potential risks, in a proactive view (Aqlan \& Lam, 2015; Giannakis \& Louis, 2011; Pujawan \& Geraldin, 2009; Tummala \& Schoenherr, 2011). For Kern et al. (2012) and Oehmen et al. (2009), this phase may treat the cause (probability reduction) as well as consequence (impact reduction).

After the selected strategy is implemented, it must also be controlled, verifying its efficiency with respect to the prioritized and treated risk. Therefore, the control phase's purpose is to evaluate the progress obtained through the implemented strategy and establish possible corrective actions in case there are any deviations and/or the strategy does not fulfill the expected goal (Giannakis \& Papadopoulos, 2016; Kern et al., 2012; Oehmen et al., 2009; Tummala \& Schoenherr, 2011).

Because the supply chain's structure and operations change regularly, new risks may emerge; confirming the importance of the monitoring phase (Kern et al., 2012).

Monitoring consists of supervising the chain in order to detect new risks, identify tendencies, probabilities and impacts (Elleuch et al., 2014; Kern et al., 2012; Oehmen et al., 2009; Pujawan \& Geraldin, 2009; Tummala \& Schoenherr, 2011; Tuncel \& Alpan, 2010). Monitoring allows for the identification of the need to rerun the process of supply chain risk management, this phase reinitiates the process of risk management, acting on emerging risks. Manuj \& Mentzer (2008a) stress the cyclic behavior of SCRM. Despite the importance of monitoring (Kern et al., 2012), the literature does not present sufficient explanations about this phase (Ho et al., 2015).

It is worth noting that during the control phase, the strategy is evaluated in regard to its result before the risk to be treated. In the monitoring phase, behavior and tendencies are observed, with the purpose of anticipating new risks.

Figure 3 presents the percentage, within the 68 selected documents, that considers each phase as part of SCRM.

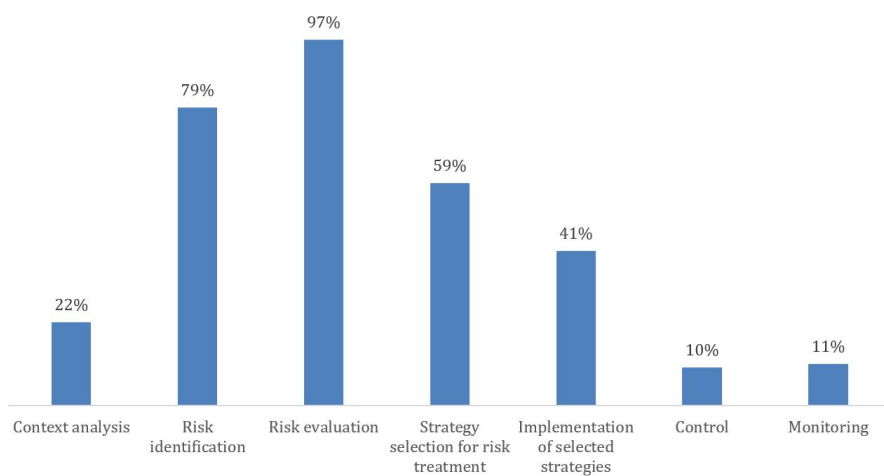

Figure 3. Distribution of the percentage of each phase considered in SCRM.

Results from Figure 3 and Table 2 emphasize the concentration of academic literature in three specific phases: risk identification, risk evaluation, and strategy 
selection for risk treatment. Context analysis, monitoring, and control are poorly explored phases.

Analyzing the authors' approaches to SCRM, it is possible to notice that only Oehmen et al. (2009) and Tummala \& Schoenherr (2011) present SCRM contemplating all seven phases presented in this study. Most authors (69\%) discussed SCRM contemplating only the phases of identification and risk analysis.

Table 2. SCRM phases.

\begin{tabular}{|c|c|}
\hline Phases & Authors that cite the phase \\
\hline $\begin{array}{l}\text { Context } \\
\text { analysis }\end{array}$ & $\begin{array}{l}\text { Berle et al. (2011), Bradley (2014), Cagliano et al. (2012), Colicchia et al. (2010), Giannakis \& } \\
\text { Louis (2011), Manuj \& Mentzer (2008a, 2008b), Oehmen et al. (2009), Olson \& Wu (2010), } \\
\text { Trkman \& McCormack (2009), Tummala \& Schoenherr (2011), Wei et al. (2010) }\end{array}$ \\
\hline $\begin{array}{c}\text { Risk } \\
\text { identification }\end{array}$ & $\begin{array}{l}\text { Amundson et al. (2014), Aqlan \& Lam (2015), Berle et al. (2011, 2013), Blackhurst et al. (2008), } \\
\text { Bogataj \& Bogataj (2007), Bradley (2014), Cagliano et al. (2012), Colicchia et al.(2010), } \\
\text { Diabat et al. (2012), Elleuch et al. (2014), Faisal et al. (2006), Fazli et al. (2015), Gaudenzi \& } \\
\text { Borghesi (2006), Ghadge et al. (2013), Giannakis \& Louis (2011), Giannakis \& Papadopoulos } \\
\text { (2016), Güller et al. (2015), Hachicha \& Elmsalmi (2014), Heckmann et al. (2015), Kern et al. } \\
\text { (2012), Kleindorfer \& Saad (2005), Klimov \& Merkuryev (2008), Lavastre et al. (2014), Lee et al. } \\
\text { (2012), Lin \& Zhou (2011), Manuj \& Mentzer (2008a, b), MeiDan et al. (2011), Micheli et al. } \\
\text { (2014), Oehmen et al. (2009), Oke \& Gopalakrishnan (2009), Olson \& Wu (2010), Pfohl et al. } \\
\text { (2010), Pfohl et al. (2011), Pradhan \& Routroy (2014), Pujawan \& Geraldin (2009), } \\
\text { Punniyamoorthy et al. (2013), Radivojević \& Gajović (2014), Rajesh et al. (2015), Ritchie \& } \\
\text { Brindley (2007), Schmitt \& Singh (2012), Schoenherr et al. (2008), Simangunsong et al. (2012), } \\
\text { Trkman \& McCormack (2009), Tummala \& Schoenherr (2011), Venkatesh et al. (2015), Vilko } \\
\text { \& Hallikas (2011), Wu et al. (2006) }\end{array}$ \\
\hline Risk evaluation & $\begin{array}{l}\text { Amundson et al. (2014), Aqlan \& Lam (2015), Atwater et al. (2014), Berle et al. (2011, 2013), } \\
\text { Blackhurst et al. (2008), Blos et al. (2015), Bogataj \& Bogataj (2007), Bradley (2014), } \\
\text { Cagliano et al. (2012), Cohen \& Kunreuther (2007), Colicchia et al. (2010), Diabat et al. (2012), } \\
\text { Elleuch et al. (2014), Faisal et al. (2006), Fang et al. (2016), Fazli et al. (2015), Franca et al. } \\
\text { (2010), Gaudenzi \& Borghesi (2006), Gemechu et al. (2015), Ghadge et al. (2013), Giannakis } \\
\text { \& Louis (2011), Giannakis \& Papadopoulos (2016), Goh et al. (2007), Güller et al. (2015), } \\
\text { Hachicha \& Elmsalmi (2014), Heckmann et al. (2015), Jung et al. (2011), Kern et al. (2012), } \\
\text { Kleindorfer \& Saad (2005), Klimov \& Merkuryev (2008), Lavastre et al. (2014), Lee et al. (2012), } \\
\text { Lin \& Zhou (2011), Manuj \& Mentzer (2008a, 2008b), MeiDan et al. (2011), Micheli et al. (2014), } \\
\text { Mizgier et al. (2015), Oehmen et al. (2009), Oke \& Gopalakrishnan (2009), Olson \& Swenseth } \\
\text { (2014), Pfohl et al. (2010), Pfohl et al. (2011), Pradhan \& Routroy (2014), Pujawan \& Geraldin } \\
\text { (2009), Punniyamoorthy et al. (2013), Radivojević \& Gajović (2014), Rajesh \& Ravi (2015), } \\
\text { Ritchie \& Brindley (2007), Schmitt \& Singh (2012), Schoenherr et al. (2008), } \\
\text { Simangunsong et al. (2012), Tapiero (2007), Trkman \& McCormack (2009), Tummala \& } \\
\text { Schoenherr (2011), Venkatesh et al. (2015), Vilko \& Hallikas (2011), Wu \& Olson (2008), } \\
\text { Wu et al. (2006), You et al. (2009) }\end{array}$ \\
\hline $\begin{array}{l}\text { Strategy } \\
\text { selection for } \\
\text { risk treatment }\end{array}$ & $\begin{array}{l}\text { Aqlan \& Lam (2015), Berle et al. (2011), Blos et al. (2015), Cohen \& Kunreuther (2007), } \\
\text { Colicchia et al. (2010), Dani \& Deep (2010), Elleuch et al. (2014), Faisal et al. (2006), } \\
\text { Fang et al. (2016), Fazli et al. (2015), Ghadge et al. (2013), Giannakis \& Louis (2011), } \\
\text { Giannakis \& Papadopoulos (2016), Hachicha \& Elmsalmi (2014), Kern et al. (2012), Kleindorfer } \\
\text { \& Saad (2005), Lavastre et al. (2014), Manuj \& Mentzer (2008a, b), Micheli et al. (2014), } \\
\text { Oehmen et al. (2009), Oke \& Gopalakrishnan (2009), Olson \& Swenseth (2014), Olson \& Wu } \\
\text { (2010), Pfohl et al. (2010), Pradhan \& Routroy (2014), Rajesh \& Ravi (2015), Rajesh et al. } \\
\text { (2015),Ritchie \& Brindley (2007), Schmitt (2011), Schmitt \& Singh (2012), Schoenherr et al. } \\
\text { (2008), Simangunsong et al. (2012), Tang (2006a), Tummala \& Schoenherr (2011) }\end{array}$ \\
\hline $\begin{array}{l}\text { Implementation } \\
\text { of selected } \\
\text { strategies }\end{array}$ & $\begin{array}{l}\text { Blos et al. (2015), Elleuch et al. (2014), Ghadge et al. (2013), Giannakis \& Louis (2011), } \\
\text { Güller et al. (2015), Kern et al. (2012), Kleindorfer \& Saad (2005), Lavastre et al. (2014), } \\
\text { Micheli et al. (2014), Pradhan \& Routroy (2014), Schmitt \& Singh (2012), Simangunsong et al. } \\
\text { (2012), Tummala \& Schoenherr (2011) }\end{array}$ \\
\hline Control & $\begin{array}{l}\text { Cohen \& Kunreuther (2007), Colicchia et al. (2010), Giannakis \& Papadopoulos (2016) } \\
\text { Kern et al. (2012), Oehmen et al. (2009), Tummala \& Schoenherr (2011) }\end{array}$ \\
\hline Monitoring & $\begin{array}{l}\text { Elleuch et al. (2014), Giannakis \& Papadopoulos (2016), Güller et al. (2015), Hachicha \& } \\
\text { Elmsalmi (2014), Kern et al. (2012), Oehmen et al. (2009), Tummala \& Schoenherr (2011) }\end{array}$ \\
\hline
\end{tabular}




\section{Tools for SCRM}

Through a full-text examination of the 68 sample documents, it was possible to identify the main tools proposed by the articles for each SCRM phase. Not all articles presented tools as shown in Figure 4.

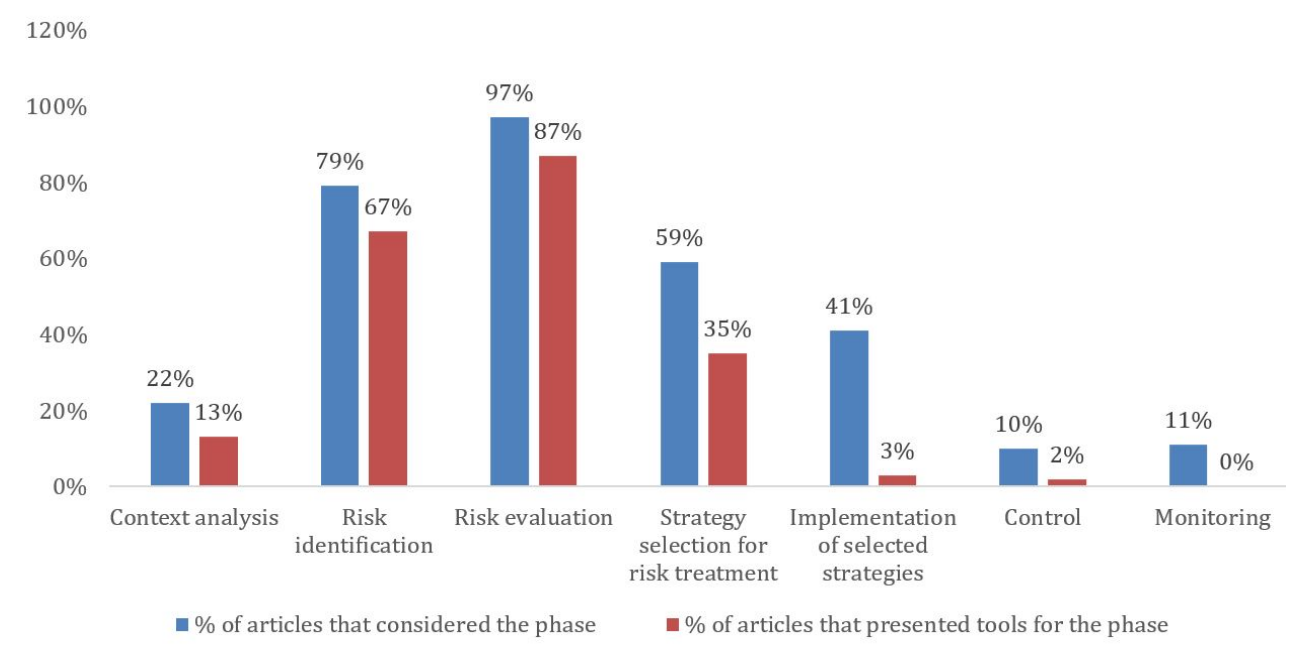

Figure 4. Percentage of the sample that presents tools and phases for SCRM.

Observing Figure 4, a concentration of academic literature efforts in presenting tools for the risk identification and evaluation phases can be noticed once again, where the number of tools found for each phase is presented in Figure 5.

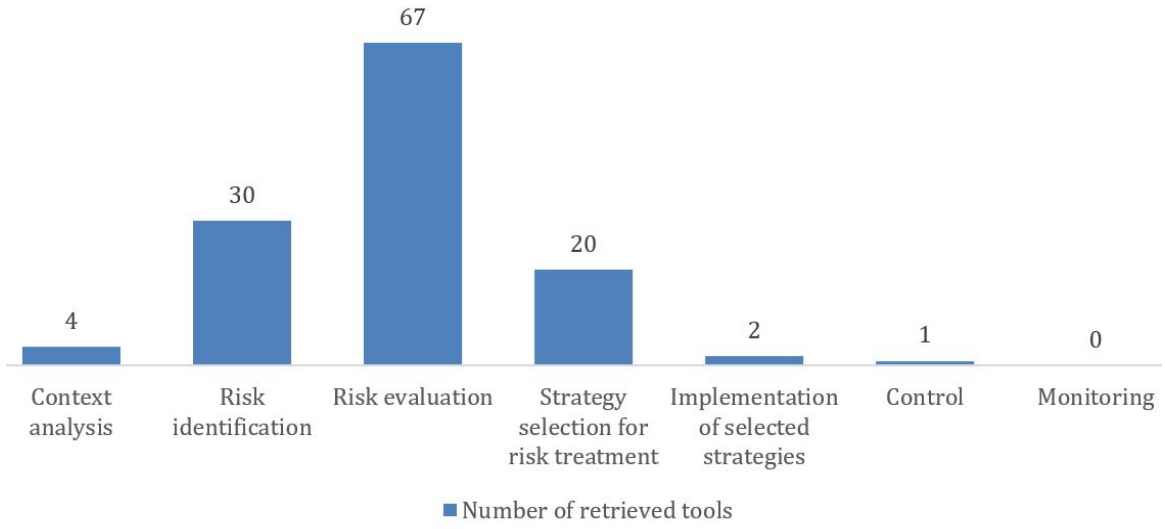

Figure 5. Number of tools for each SCRM phase.

Figures 4 and 5 evidence the need for the development of studies in SCRM, especially concerning the phases of control and monitoring. Much was explored regarding the phases of identification, risk evaluation and strategy selection, leaving the other phases devoid of studies and implementation propositions.

The next paragraphs present the main tools proposed for each phase of SCRM. Tools that were cited the most and with at least two citations were considered in the analysis. 
The most cited tools for the context analysis phase are supply chain mapping (Bradley, 2014; Cagliano et al., 2012; Colicchia et al., 2010; Lin \& Zhou, 2011; Oehmen et al., 2009); and interviews (Berle et al., 2011; Lavastre et al., 2014).

For the risk identification phase, the main tools presented were expert opinion (Aqlan \& Lam, 2015; Berle et al., 2013; Diabat et al., 2012; Fazli et al., 2015; Lavastre et al., 2014; MeiDan et al., 2011; Micheli et al., 2014; Punniyamoorthy et al., 2013; Radivojević \& Gajović, 2014; Schoenherr et al., 2008); interviews (Blackhurst et al., 2008; Bradley, 2014; Lavastre et al., 2014; Lin \& Zhou, 2011; Lockamy \& McCormack, 2012; Oke \& Gopalakrishnan, 2009; Schmitt \& Singh, 2012; Vilko \& Hallikas, 2011; Wu et al., 2006); literature review (Diabat et al., 2012; Fazli et al., 2015; MeiDan et al., 2011; Punniyamoorthy et al., 2013; Schmitt \& Singh, 2012; Trkman \& McCormack, 2009; Venkatesh et al., 2015; Wu et al., 2016); and brainstorm (Berle et al., 2013; Bradley, 2014; Hachicha \& Elmsalmi, 2014; Oehmen et al., 2009; Pradhan \& Routroy, 2014; Venkatesh et al., 2015). Figure 6 presents all tools that obtained at least two citations for the risk identification phase.

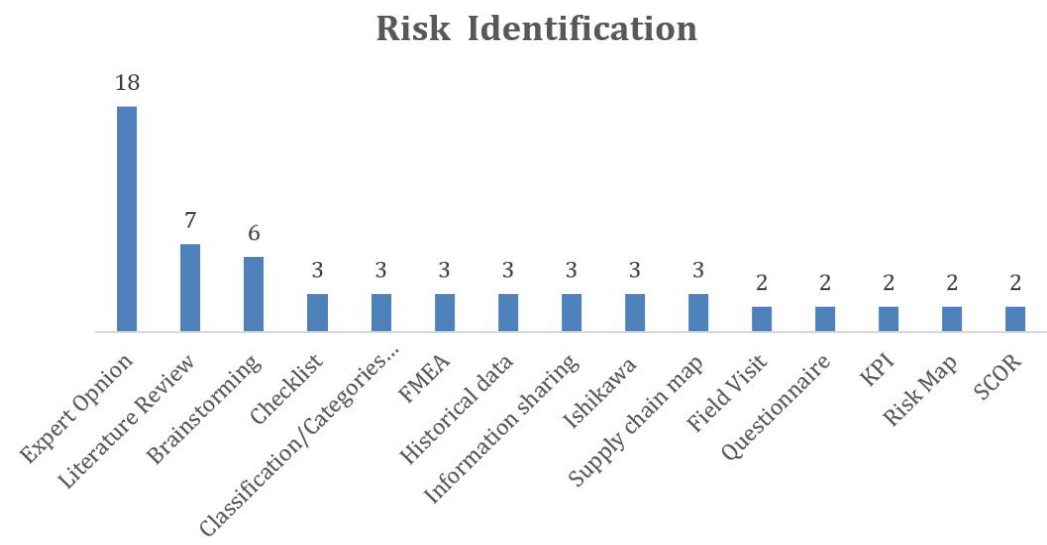

Figure 6. Tools for the risk identification phase and number of citations per tool.

It is worth noting the possibility of combining tools so that a phase's goal is achieved. For example, according to Punniyamoorthy et al. (2013), after completing a literature review on the potential risks of the studied chain, the results should be presented to a group of specialists. The group must evaluate if the risk indeed exists for the assessed case, and decide whether it should be included on the list of potential risks for treatment. That is, the tools relate and can be complementary.

For the risk evaluation phase, proposed tools were simulation (Berle et al., 2013; Gemechu et al., 2015; Giannakis \& Papadopoulos, 2016; Güller et al., 2015; Heckmann et al., 2015; Klimov \& Merkuryev, 2008; Lee et al., 2012; Mizgier et al., 2015; Oehmen et al., 2009; Olson \& Wu, 2010; Schmitt \& Singh, 2012; Tummala \& Schoenherr, 2011; Vilko \& Hallikas, 2011; Wei et al., 2010; Wu \& Olson, 2008; You et al., 2009), emphasizing the Monte Carlo simulation (Gemechu et al., 2015; Lee et al., 2012; Mizgier et al., 2015; Oehmen et al., 2009; Tummala \& Schoenherr, 2011; Vilko \& Hallikas, 2011; Wei et al., 2010; Wu \& Olson, 2008; You et al., 2009), expert opinion (Aqlan \& Lam, 2015; Bradley, 2014; Cohen \& Kunreuther, 2007; Gaudenzi \& Borghesi, 2006; Kleindorfer \& Saad, 2005; Klimov \& Merkuryev, 2008; MeiDan et al., 2011; Olson \& Swenseth, 2014; Pradhan \& Routroy, 2014; Punniyamoorthy et al., 2013; Tummala \& Schoenherr, 2011; Vilko \& Hallikas, 2011); 
AHP - analytic hierarchy process (Gaudenzi \& Borghesi, 2006; Giannakis \& Papadopoulos, 2016; Micheli et al., 2014; Olson \& Swenseth, 2014; Olson \& Wu, 2010; Radivojević \& Gajović, 2014; Schoenherr et al., 2008; Wu et al., 2006); FMEA - Failure Mode and Effect Analysis (Bradley, 2014; Giannakis \& Louis, 2011; Giannakis \& Papadopoulos, 2016; Lee et al., 2012; Oehmen et al., 2009; Pradhan \& Routroy, 2014) and Delphi (Gaudenzi \& Borghesi, 2006; Ghadge et al., 2013; Manuj \& Mentzer, 2008a; Tummala \& Schoenherr, 2011; Vilko \& Hallikas, 2011). Widening the perception of the most cited tools, Figure 7 displays all tools that presented at least two citations for the risk evaluation phase.

\section{Risk Evaluation}

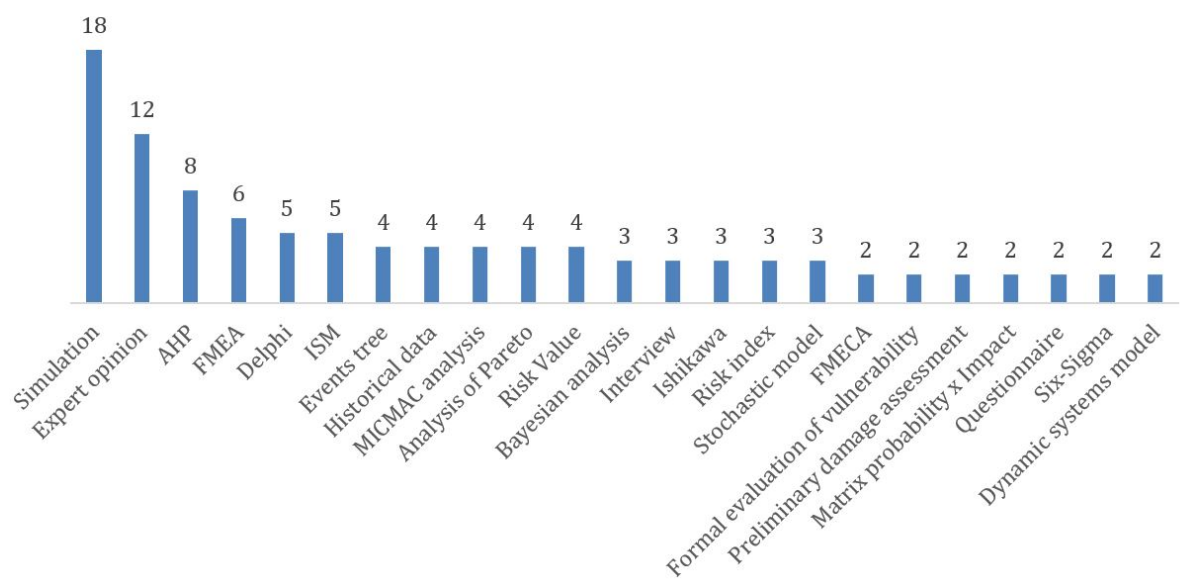

Figure 7. Tools for the risk evaluation phase and number of citations per tool.

For the strategy selection for risk treatment phase, the main cited tools were cost-benefit analysis (Berle et al., 2011; Colicchia et al., 2010; Oehmen et al., 2009; Tang, 2006a; Tummala \& Schoenherr, 2011); expert opinion (Manuj \& Mentzer, 2008b; Micheli et al., 2014; Schmitt, 2011); interviews (Giannakis \& Papadopoulos, 2016; Lavastre et al., 2014; Manuj \& Mentzer, 2008b); AHP (Elleuch et al., 2014; Schoenherr et al., 2008) and ISM - Interpretive Structural Modeling (Faisal et al., 2006; Rajesh et al., 2015).

For the strategy implementation for risk treatment phase no tools with an expressive number of citations were found, only two tools were found with one citation each, they were action plan (Pradhan \& Routroy, 2014) and the convenience function approach (Elleuch et al., 2014).

The only proposed tool for the risk control phase was updating risk information. This tool consists of updating information for the prioritized risk, verifying the efficiency of the implemented treatment strategy (Tummala \& Schoenherr, 2011).

No tool was proposed for the risk monitoring phase. Contrary to expectations, no author cites the use of $\mathrm{KPI}$ as a possible tool for this phase.

A research gap is observed after document analysis regarding the phases of strategy implementation for risk treatment, control, and monitoring, since they were insufficiently explored in the literature with respect to practical implementations. 


\section{Compilation of results from scrm phases and their tools}

The goal of this section is to summarize the information collected regarding the phases and tools for SCRM. The data gathered concerning the tools for each phase of supply chain risk management show that the use of certain tools is not exclusive to a single phase. Table 3 presents the different tools proposed by the sample documents and their application in the SCRM phases.

Table 3. Phases and tools.

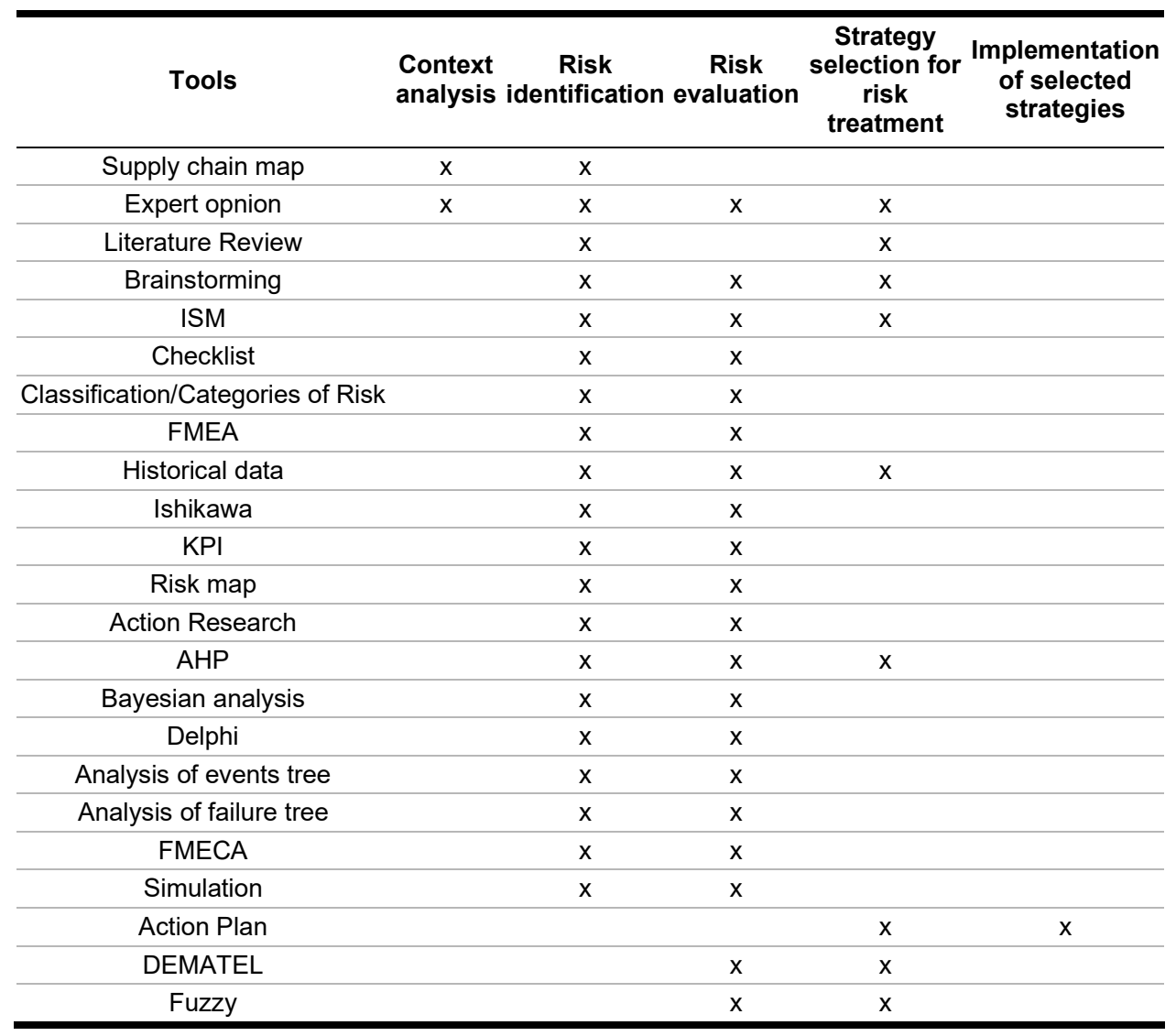

The tools presented in Table 2 are applied with different goals to each phase. Even though expert opinion, for example, is present in different phases, the role of the specialist changes as the supply chain risk management process moves forward. It is also possible to observe tools with multiple steps, where each step meets the purpose of a phase, such as the ISM proposed by Diabat et al. (2012), Faisal et al. (2006), Hachicha \& Elmsalmi (2014), Pfohl et al. (2011) and Venkatesh et al. (2015).

Based on the phases and tools gathered, a global framework for supply chain risk management, represented in Figure 8, can be proposed, where the phases for SCRM and their tools are highlighted. 


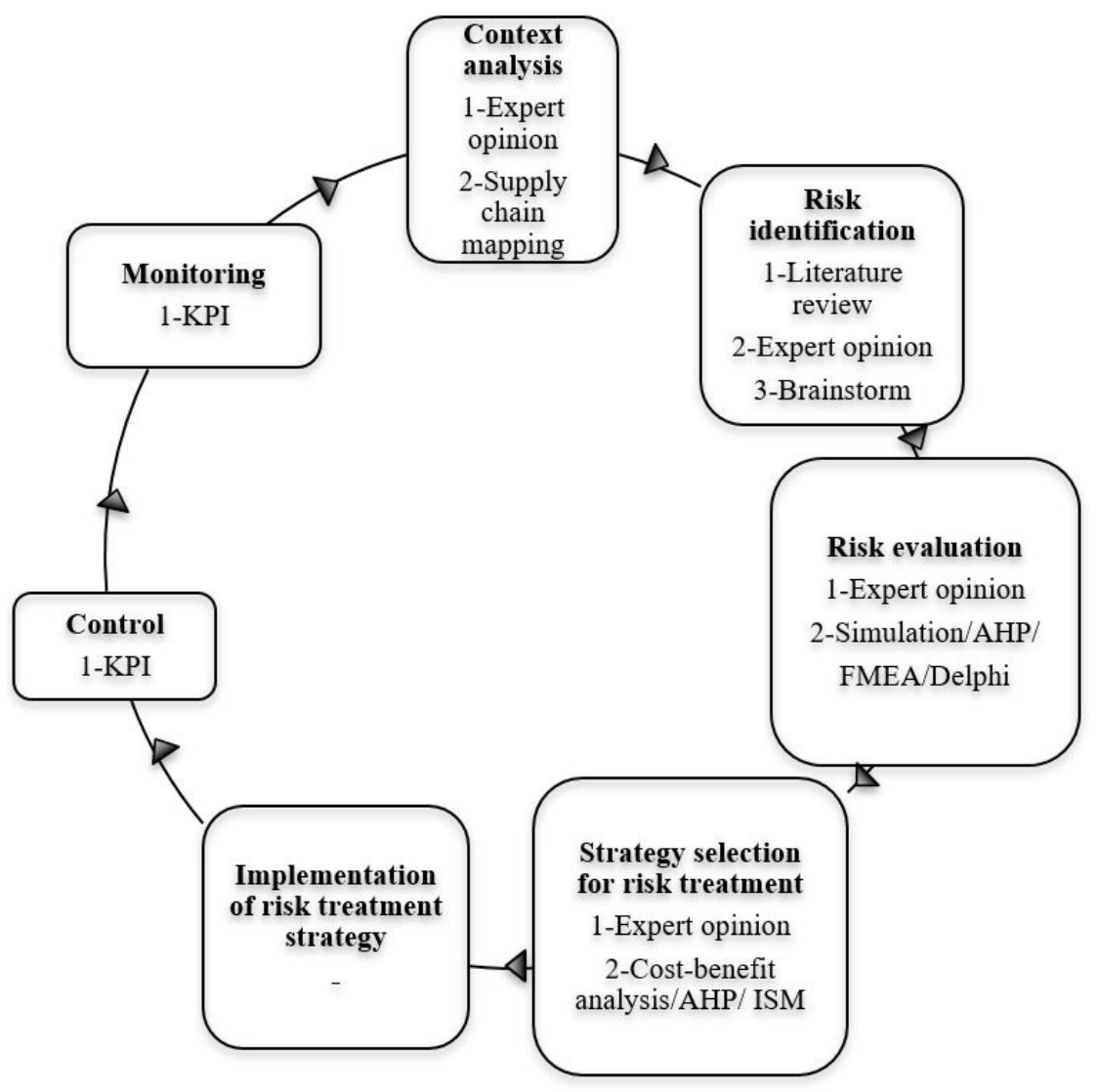

Figure 8. Framework for SCRM.

It can be observed from Figure 8 that the literature presents "expert opinion" as a common tool for most phases, this is partly due to the fact that many chains still do not have a mature SCRM model. Therefore, the starting point for risk management becomes the experience of those involved in the processes that comprise chain management. The absence of documented information and structured tools should not prevent SCRM, once the expertise of those involved in the process could be used until new tools may be added to SCRM.

The framework represented by Figure 8 suggests an implementation guide for SCRM, the tools were numbered in order of necessity, as to facilitate their use. Exemplifying, so that the scope of the chain where the risk will be managed can be defined, the starting point may be an issue experimented by a focal business. From there, members of the chain considered critical to the issue are identified, allowing for the definition of first layer suppliers. When reporting the problem to first-tier suppliers, these may identify that other suppliers could be included (second-tier suppliers, in relation to the focal business), and so on. A similar approach is presented in Ceryno et al. (2015) for scope definition in SCRM. Once the critical suppliers for a given problem are defined, the studied chain may be mapped. For risk identification, in case information to support this phase is insufficient, a literature review could be performed regarding chains of similar fields, in an attempt to raise the main issues approached in the literature. This survey may be used as an initial list to be validated and/or complemented by specialists, that may be stimulated to include new risks through tools 
such as brainstorm. During risk evaluation, when probabilities, impacts and subsequent prioritization are defined, expert opinion may once again be used in several ways, for example through tools such as AHP, FMEA, DELPHI and simulation.

Regarding the selection of strategy to be implemented, expert opinion may assist decision making. Naturally, in chains where SCRM is more mature, this tool should be combined with more sophisticated ones, such as a cost-benefit analysis, AHP, and ISM. Once the strategy is implemented, it should be monitored regarding its efficiency. Although the literature does not present tools for this phase, the use of performance indicators related to the desired performance of the chain regarding the treated risk is suggested as a way of identifying deviations with respect to what was planned. The same applies to the monitoring phase since the chain must be constantly evaluated so that new risks may be identified. The use of KPI for this phase is justifiable, once activities related to SCRM are only valid if the identified risks interfere with the supply chain's performance (Wagner \& Bode, 2008). The importance of using KPI in supply chains as a way of overseeing the gap between what is planned and what is executed as to identify potential issues and improvement areas has already been previously addressed, for example, in Wagner \& Bode (2008) and Chae (2009). Studies such as Neely et al. (1997) and Beamon (1999) may suit as a foundation for the definition of indicators and their implementation, focusing on supporting the SCRM process.

\section{Conclusions}

The growing interest in supply chain risk management was identified through a search in academic databases, focusing on the different phases and tools presented by the literature. Seven phases were identified, and it was possible to determine the existence of a research gap concerning the last three phases (implementation of risk treatment strategy, control, and monitoring). The low number of articles that treat these phases as well as the limited number of tools presented to address them confirms the gap. The gap observed in this paper corroborates findings from Ho et al., (2015).

An important aspect examined in this research concerns the goals of the control and monitoring phases, as they were treated as synonyms by the literature. Therefore, there is no consensus regarding these phases' definitions and goals (e.g. Kern et al., 2012; Giannakis \& Papadopoulos, 2016). This study sought to remedy this gap, since it presents the role of each SCRM phase and their goals.

The main tools for SCRM where presented in this study, where another research gap was observed: the lack of theoretical and practical studies regarding the phases of implementation of risk treatment strategy, control and monitoring, justifying the low number of proposed tools or even their absence for these phases, corroborating König \& Spinler (2016), who point to the lack of SCRM global practical applications.

Since identification and evaluation of risks are the most studied phases, the elevated number of tools found in the academic literature for these phases in comparison to the rest is not surprising. The use of simulation is strongly emphasized for the risk evaluation phase, although some articles present it equally as the chosen option for the identification phase.

This study takes the first step in the elaboration of a global implementation guide for SCRM, once it highlights the phases that compose supply chain risk management and the tools that enable their application as its main result. Provides important contributions to the application and research in SCRM. 
This study contributes to SCRM in an important manner, in six main aspects. First, it offers a taxonomy that allows for the classification of the phases and proper tools for each phase of risk management in the SC. Second, presents which tools should be used in which phases of SCRM in a structured manner. Third, offers a framework for SCRM, constituting a new and practical guide for SCRM implementation. Fourth, raises the use of KPIs in SCRM, highlighting their relevance and in which management phases they should be used. Fifth, by indicating least studied phases and least used tools, opens new avenues for future research, emphasizing the need for new tools applied above all to the phases of implementation, control and monitoring. Finally, and consistent with what is proposed in recent literature in operations management (e.g., Torraco, 2005; Denyer \& Tranfield, 2009; Fahimnia et al., 2015; Thomé et al., 2016), this study evidences the potential use of systematic literature reviews as a supply chain risk management confrontation tool, offering a taxonomy, a framework and a future agenda for useful research for the academy and for the practice of supply chain risk management.

\section{References}

Amundson, J., Brown, A., Grabowski, M., \& Badurdeen, F. (2014). Life-cycle risk modeling: alternate methods using bayesian belief networks. Procedia CIRP, 17, 320-325. http://doi.org/http://dx.doi.org/10.1016/j.procir.2014.02.029.

Aqlan, F., \& Lam, S. S. (2015). A fuzzy-based integrated framework for supply chain risk assessment. International Journal of Production Economics, 161, 54-63. http://dx.doi.org/10.1016/j.ijpe.2014.11.013.

Atwater, C., Gopalan, R., Lancioni, R., \& Hunt, J. (2014). Measuring supply chain risk: predicting motor carriers ability to withstand disruptive environmental change using conjoint analysis. Transportation Research Part C, Emerging Technologies, 48, 360-378. http://dx.doi.org/10.1016/j.trc.2014.09.009.

Beamon, B. M. (1999). Measuring supply chain performance. International Journal of Operations \& Production Management, 9(3), 275-292. http://dx.doi.org/10.1108/01443579910249714.

Berle, Ø., Asbjørnslett, B. E., \& Rice, J. B. (2011). Formal vulnerability assessment of a maritime transportation system. Reliability Engineering \& System Safety, 96(6), 696-705. http://dx.doi.org/10.1016/j.ress.2010.12.011.

Berle, Ø., Norstad, I., \& Asbjørnslett, B. E. (2013). Optimization, risk assessment and resilience in LNG transportation systems. Supply Chain Management, 18(3), 253-264. http://dx.doi.org/10.1108/SCM-03-2012-0109.

Blackhurst, J. V., Scheibe, K. P., \& Johnson, D. J. (2008). Supplier risk assessment and monitoring for the automotive industry. International Journal of Physical Distribution \& Logistics Management, 38(2), 143-165. http://dx.doi.org/10.1108/09600030810861215.

Blos, M. F., Hoeflich, S. L., \& Miyagi, P. E. (2015). A general supply chain continuity management framework. Procedia Computer Science, 55, 1160-1164. http://dx.doi.org/10.1016/j.procs.2015.07.087.

Bogataj, D., \& Bogataj, M. (2007). Measuring the supply chain risk and vulnerability in frequency space. International Journal of Production Economics, 108(1), 291-301. http://dx.doi.org/10.1016/j.ijpe.2006.12.017.

Bradley, J. R. (2014). An improved method for managing catastrophic supply chain disruptions. Business Horizons, 57(4), 483-495. http://dx.doi.org/10.1016/j.bushor.2014.03.003. 
Cagliano, A. C., De Marco, A., Grimaldi, S., \& Rafele, C. (2012). An integrated approach to supply chain risk analysis. Journal of Risk Research, 15(7), 817-840. http://dx.doi.org/10.1080/13669877.2012.666757.

Campbell Collaboration. (2014). Campbell collaboration systematic reviews: policies and guidelines (Campbell Policies and Guidelines Series, No. 1). Oslo: The Campbell Collaboration. http://dx.doi.org/10.4073/cpg.2016.1.

Ceryno, P. S., Scavarda, L. F., \& Klingebiel, K. (2015). Supply chain risk: empirical research in the automotive industry. Journal of Risk Research, 18(9), 1145-1164. http://dx.doi.org/10.1080/13669877.2014.913662.

Chae, B. K. (2009). perspective. Supply Chain Management, 14(6), 422-428. http://dx.doi.org/10.1108/13598540910995192.

Cohen, M. A., \& Kunreuther, H. (2007). Operations risk management: overview of paul kleindorfer's contributions. Production and Operations Management, 16(5), 525-541. http://dx.doi.org/10.1111/j.1937-5956.2007.tb00278.x.

Colicchia, C., Dallari, F., \& Melacini, M. (2010). Increasing supply chain resilience in a global sourcing context. Production Planning and Control, 21(7), 680-694. http://dx.doi.org/10.1080/09537280903551969.

Cooper, H. M. (1988). Organizing knowledge syntheses: A taxonomy of literature reviews. Knowledge in Society, 1(1), 104-126. http://dx.doi.org/10.1007/BF03177550.

Cooper, H. M. (2010). Research synthesis and meta-analysis: a step-by-step approach (Applied Social Research Methods Series, Vol. 4). Thousand Oaks: SAGE Publications, Inc. http://doi.org/10.1093/bfgp/elp014.

Craighead, C. W., Blackhurst, J., Rungtusanatham, M. J., \& Handfield, R. B. (2007). The severity of supply chain disruptions: design characteristics and mitigation capabilities. Decision Sciences, 38(1), 131-156. http://dx.doi.org/10.1111/j.1540-5915.2007.00151.x.

Cucchiella, F., \& Gastaldi, M. (2006). Risk management in supply chain: a real option approach. Journal of Manufacturing Technology Management, 17(6), 700-720. http://dx.doi.org/10.1108/17410380610678756.

Dani, S., \& Deep, A. (2010). Fragile food supply chains: reacting to risks. International Journal of Logistics: Research and Applications, 13(5), 395-410. http://dx.doi.org/10.1080/13675567.2010.518564.

Denyer, D., \& Tranfield, D. (2009). Producing a systematic review. In D. Buchanan \& A. Bryman (Eds.), The sage handbook of organizational research methods. London: Sage. pp. 671689.

Diabat, A., Govindan, K., \& Panicker, V. V. (2012). Supply chain risk management and its mitigation in a food industry. International Journal of Production Research, 50(11), 30393050. http://dx.doi.org/10.1080/00207543.2011.588619.

Elleuch, H., Hachicha, W., \& Chabchoub, H. (2014). A combined approach for supply chain risk management: description and application to a real hospital pharmaceutical case study. Journal of Risk Research, 17(5), 641-663. http://dx.doi.org/10.1080/13669877.2013.815653.

Esmaeilikia, M., Fahimnia, B., Sarkis, J., Govindan, K., Kumar, A., \& Mo, J. (2016). A tactical supply chain planning model with multiple flexibility options: an empirical evaluation. Annals of Operations Research, 244(2), 429-454. http://dx.doi.org/10.1007/s10479-013-1513-2.

Fahimnia, B., Tang, C. S., Davarzani, H., \& Sarkis, J. (2015). Quantitative models for managing supply chain risks: a review. European Journal of Operational Research, 247(1), 1-15. http://dx.doi.org/10.1016/j.ejor.2015.04.034.

Faisal, M. N., Banwet, D. K., \& Shankar, R. (2006). Mapping supply chains on risk and customer sensitivity dimensions. Industrial Management \& Data Systems, 106(6). http://dx.doi.org/10.1108/02635570610671533. 
Fan, H., Li, G., Sun, H., \& Cheng, T. C. E. (2016). An information processing perspective on supply chain risk management: Antecedents, mechanism, and consequences. International Journal of Production Economics, 185, 63-75. http://dx.doi.org/10.1016/j.ijpe.2016.11.015.

Fang, C., Liao, X., \& Xie, M. (2016). A hybrid risks-informed approach for the selection of supplier portfolio. International Journal of Production Research, 54(7), 2019-2034. http://doi.org/10.1080/00207543.2015.1076947.

Fazli, S., Kiani Mavi, R., \& Vosooghidizaji, M. (2015). Crude oil supply chain risk management with DEMATEL-ANP. Operations Research, 15(3), 453-480. http://dx.doi.org/10.1007/s12351-015-0182-0.

Franca, R. B., Jones, E. C., Richards, C. N., \& Carlson, J. P. (2010). Multi-objective stochastic supply chain modeling to evaluate tradeoffs between profit and quality. International Journal of Production Economics, 127(2), 292-299. http://dx.doi.org/10.1016/j.jpe.2009.09.005.

Gaudenzi, B., \& Borghesi, A. (2006). Managing risks in the supply chain using the AHP method. International Journal of Logistics Management, 17(1), 114-136. http://dx.doi.org/10.1108/09574090610663464.

Gemechu, E. D., Helbig, C., Sonnemann, G., Thorenz, A., \& Tuma, A. (2015). Import-based indicator for the geopolitical supply risk of raw materials in life cycle sustainability assessments. Journal of Industrial Ecology

Ghadge, A., Dani, S., Chester, M., \& Kalawsky, R. (2013). A systems approach for modelling supply chain risks. Supply Chain Management, 18(5), 523-538. http://dx.doi.org/10.1108/SCM-11-2012-0366.

Giannakis, M., \& Louis, M. (2011). A multi-agent based framework for supply chain risk management. Journal of Purchasing and Supply Management, 17(1), 23-31. http://dx.doi.org/10.1016/j.pursup.2010.05.001.

Giannakis, M., \& Papadopoulos, T. (2016). Supply chain sustainability: a risk management approach. International Journal of Production Economics, 171, 455-470. http://dx.doi.org/10.1016/j.ijpe.2015.06.032.

Goh, M., Lim, J. Y. S., \& Meng, F. (2007). A stochastic model for risk management in global supply chain networks. European Journal of Operational Research, 182(1), 164-173. http://dx.doi.org/10.1016/j.ejor.2006.08.028.

Gredal, P., Panyi, Z., Kinra, A., \& Kotzab, H. (2017). What hinders the implementation of the supply chain risk management process into practice organizations? In M. Freitag, $\mathrm{H}$. Kotzab, \& J. Pannek (Eds.), Dynamics in Logistics. Lecture Notes in Logistics (pp. 151161). Cham: Springer International Publishing. http://dx.doi.org/10.1007/978-3-319-451176_14

Güller, M., Koc, E., Hegmanns, T., Henke, M., \& Noche, B. (2015). A simulation-based decision support framework for real-time supply chain risk management. International Journal of Advanced Logistics, 4(1), 17-26. http://dx.doi.org/10.1080/2287108X.2015.1008948.

Hachicha, W., \& Elmsalmi, M. (2014). An integrated approach based-structural modeling for risk prioritization in supply network management. Journal of Risk Research, 17(10), 1301-1324. http://dx.doi.org/10.1080/13669877.2013.841734.

Harland, C., Brenchley, R., \& Walker, H. (2003). Risk in supply networks. Journal of Purchasing and Supply Management, 9(2), 51-62. http://dx.doi.org/10.1016/S1478-4092(03)00004-9.

Heckmann, I., Comes, T., \& Nickel, S. (2015). A critical review on supply chain risk - Definition, measure and modeling. Omega (United Kingdom), 52, 119-132. http://dx.doi.org/10.1016/j.omega.2014.10.004.

Higgins, J. P. T., \& Green, S. (2008). Cochrane handbook for systematic reviews of interventions. Sussex: Wiley. http://dx.doi.org/10.1002/9780470712184. 
Hirsch, J. E. (2005). An index to quantify an individual's scientific research output. Proceedings of the National Academy of Sciences of the United States of America, 102(46). 1656916572. http://dx.doi.org/10.1073/pnas.0507655102.

Ho, W., Zheng, T., Yildiz, H., \& Talluri, S. (2015). Supply chain risk management: a literature review. International Journal of Production Research, 53(16), 5031-5069. http://dx.doi.org/10.1080/00207543.2015.1030467.

Jung, K., Lim, Y., \& Oh, J. (2011). A model for measuring supplier risk: do operational capability indicators enhance the prediction accuracy of supplier risk? British Journal of Management, 22(4), 609-627. http://dx.doi.org/10.1111/j.1467-8551.2010.00697.x.

Jüttner, U. (2005). Supply chain risk management: understanding the business requirements from a practitioner perspective. International Journal of Logistics Management, 16(1), 120141. http://dx.doi.org/10.1108/09574090510617385.

Kern, D., Moser, R., Hartmann, E., \& Moder, M. (2012). Supply risk management: model development and empirical analysis. International Journal of Physical Distribution \& Logistics Management, 42(1), 60-82. http://dx.doi.org/10.1108/09600031211202472.

Kleindorfer, P. R., \& Saad, G. H. (2005). Managing disruption risks in supply chains. Production and Operations Management, 14(1), 53-68. http://dx.doi.org/10.1111/j.19375956.2005.tb00009.x.

Klimov, R., \& Merkuryev, Y. (2008). Simulation model for supply chain reliability evaluation. Technological and Economic Development of Economy, 14(3), 300-311. http://dx.doi.org/10.3846/1392-8619.2008.14.300-311.

König, A., \& Spinler, S. (2016). The effect of logistics outsourcing on the supply chain vulnerability of shippers: development of a conceptual risk management framework. International Journal of Logistics Management, 27(1), 122-141. http://dx.doi.org/10.1108/IJLM-03-2014-0043.

Krippendorff, K. (2004). Content analysis: An introduction to its methodology. Thousand Oaks: Sage.

Lavastre, O., Gunasekaran, A., \& Spalanzani, A. (2014). Effect of firm characteristics, supplier relationships and techniques used on Supply Chain Risk Management (SCRM): an empirical investigation on French industrial firms. International Journal of Production Research, 52(11), 3381-3403. http://dx.doi.org/10.1080/00207543.2013.878057.

Lee, C. K. M., Ching Yeung, Y., \& Hong, Z. (2012). An integrated framework for outsourcing risk management. Industrial Management \& Data Systems, 112(4), 541-558. http://dx.doi.org/10.1108/02635571211225477.

Lin, Y., \& Zhou, L. (2011). The impacts of product design changes on supply chain risk: a case study. International Journal of Physical Distribution \& Logistics Management, 41(2), 162186. http://dx.doi.org/10.1108/09600031111118549.

Lockamy, A., 3rd, \& McCormack, K. (2012). Modeling supplier risks using Bayesian networks. Industrial Management \& Data Systems, 112(2), 313-333. http://dx.doi.org/10.1108/02635571211204317.

Manuj, I., \& Mentzer, J. T. (2008a). Global supply chain risk management. Journal of Business Logistics, 29(1), 133-IX. http://dx.doi.org/10.1002/j.2158-1592.2008.tb00072.x.

Manuj, I., \& Mentzer, J. T. (2008b). Global supply chain risk management strategies. International Journal of Physical Distribution \& Logistics Management, 38(3), 192-223. http://dx.doi.org/10.1108/09600030810866986.

Manuj, I., Esper, T. L., \& Stank, T. P. (2014). Supply chain risk management approaches under different conditions of risk. Journal of Business Logistics, 35(3), 241-258. http://dx.doi.org/10.1111/jbl.12051.

MeiDan, X., Ye, L., \& ZhiQiang, S. (2011). On the measure method of electronic supply chain risk. Procedia Engineering, 15, 4805-4813. http://dx.doi.org/10.1016/j.proeng.2011.08.898. 
Micheli, G. J. L., Mogre, R., \& Perego, A. (2014). How to choose mitigation measures for supply chain risks. International Journal of Production Research, 52(1), 117-129. http://dx.doi.org/10.1080/00207543.2013.828170.

Mizgier, K. J., Wagner, S. M., \& Jüttner, M. P. (2015). Disentangling diversification in supply chain networks. International Journal of Production Economics, 162, 115-124. http://dx.doi.org/10.1016/j.ijpe.2015.01.007.

Neuendorf, K. A. (2002). The Content Analysis Guidebook. Thousand Oaks: Sage Publications.

Neely, A., Richards, H., Mills, J., Platts, K., \& Bourne, M. (1997). Designing performance measures: a structured approach. International journal of operations \& Production management, 17(11), 1131-1152. http://dx.doi.org/10.1108/01443579710177888.

Oehmen, J., Ziegenbein, A., Alard, R., \& Schonsleben, P. (2009). System-oriented supply chain risk management. Production Planning and Control, 20(4), 343-361. http://dx.doi.org/10.1080/09537280902843789.

Oke, A., \& Gopalakrishnan, M. (2009). Managing disruptions in supply chains: a case study of a retail supply chain. International Journal of Production Economics, 118(1), 168-174. http://dx.doi.org/10.1016/j.jpe.2008.08.045.

Olcott, G., \& Oliver, N. (2014). Social capital, sensemaking, and recovery. California Management Review, 56(2), 5-22. http://dx.doi.org/10.1525/cmr.2014.56.2.5.

Olson, D. L., \& Swenseth, S. R. (2014). Trade-offs in supply chain system risk mitigation. Systems Research and Behavioral Science, 31(4), 565-579. http://dx.doi.org/10.1002/sres.2299.

Olson, D. L., \& Wu, D. D. (2010). A review of enterprise risk management in supply chain. Kybernetes, 39(5), 694-706. http://dx.doi.org/10.1108/03684921011043198.

Petticrew, R., \& Roberts, H. (2006). Systematic reviews in the social sciences: a practical guide. Malden, MA: Blackwell. http://dx.doi.org/10.1002/9780470754887.

Pfohl, H., Gallus, P., \& Thomas, D. (2011). Interpretive structural modeling of supply chain risks. International Journal of Physical Distribution \& Logistics Management, 41(9), 839-859. http://dx.doi.org/10.1108/09600031111175816.

Pfohl, H.-C., Köhler, H., \& Thomas, D. (2010). State of the art in supply chain risk management research: empirical and conceptual findings and a roadmap for the implementation in practice. Logistics Research, 2(1), 33-44. http://dx.doi.org/10.1007/s12159-010-0023-8.

Pradhan, S. K., \& Routroy, S. (2014). Analyzing the supply chain risk issues for an Indian manufacturing company. Journal of Advances in Management Research, 11(2), 144-162. http://dx.doi.org/10.1108/JAMR-11-2012-0047.

Pujawan, I. N., \& Geraldin, L. H. (2009). House of risk: a model for proactive supply chain risk management. Business Process Management Journal, 15(6), 953-967. http://dx.doi.org/10.1108/14637150911003801.

Punniyamoorthy, M., Thamaraiselvan, N., \& Manikandan, L. (2013). Assessment of supply chain risk: scale development and validation. Benchmarking, 20(1), 79-105. http://dx.doi.org/10.1108/14635771311299506.

Radivojević, G., \& Gajović, V. (2014). Supply chain risk modeling by AHP and Fuzzy AHP methods. Journal of Risk Research, 17(3), 337-352. http://dx.doi.org/10.1080/13669877.2013.808689.

Rajesh, R., \& Ravi, V. (2015). Modeling enablers of supply chain risk mitigation in electronic supply chains: A Grey--DEMATEL approach. Computers \& Industrial Engineering, 87, 126139. http://dx.doi.org/10.1016/j.cie.2015.04.028.

Rajesh, R., Ravi, V., \& Venkata Rao, R. (2015). Selection of risk mitigation strategy in electronic supply chains using grey theory and digraph-matrix approaches. International Journal of Production Research, 53(1), 238-257. http://dx.doi.org/10.1080/00207543.2014.948579. 
Ritchie, B., \& Brindley, C. (2007). Supply chain risk management and performance: a guiding framework for future development. International Journal of Operations \& Production Management, 27(3), 303-322. http://dx.doi.org/10.1108/01443570710725563.

Schmitt, A. J. (2011). Strategies for customer service level protection under multi-echelon supply chain disruption risk. Transportation Research Part B: Methodological, 45(8), 12661283. http://dx.doi.org/10.1016/j.trb.2011.02.008.

Schmitt, A. J., \& Singh, M. (2012). A quantitative analysis of disruption risk in a multi-echelon supply chain. International Journal of Production Economics, 139(1), 22-32. http://dx.doi.org/10.1016/j.jpe.2012.01.004.

Schoenherr, T., Rao Tummala, V. M., \& Harrison, T. P. (2008). Assessing supply chain risks with the analytic hierarchy process: providing decision support for the offshoring decision by a US manufacturing company. Journal of Purchasing and Supply Management, 14(2), 100-111. http://dx.doi.org/10.1016/j.pursup.2008.01.008.

Simangunsong, E., Hendry, L. C., \& Stevenson, M. (2012). Supply-chain uncertainty: a review and theoretical foundation for future research. International Journal of Production Research, 50(16), 4493-4523. http://dx.doi.org/10.1080/00207543.2011.613864.

Sofyalığlu, Ç., \& Kartal, B. (2012). The selection of global supply chain risk management strategies by using fuzzy analytical hierarchy process - a case from Turkey. Procedia: Social and Behavioral Sciences, 58, 1448-1457. http://dx.doi.org/10.1016/j.sbspro.2012.09.1131.

Tang, C. (2006a). Robust strategies for mitigating supply chain disruptions. International Journal of Logistics, 9(1), 33-45. http://dx.doi.org/10.1080/13675560500405584.

Tang, C. S. (2006b). Perspectives in supply chain risk management. International Journal of Production Economics, 103(2), 451-488. http://dx.doi.org/10.1016/j.ijpe.2005.12.006.

Tang, O., \& Nurmaya Musa, S. (2011). Identifying risk issues and research advancements in supply chain risk management. International Journal of Production Economics, 133(1), 2534. http://dx.doi.org/10.1016/j.ijpe.2010.06.013.

Tapiero, C. S. (2007). Consumers risk and quality control in a collaborative supply chain. European Journal of Operational Research, 182(2), 683-694. http://dx.doi.org/10.1016/j.ejor.2006.07.039.

Thomé, A. M. T., Hollmann, R. L., \& Carmo, L. F. R. R. S. (2014). Research synthesis in collaborative planning forecast and replenishment. Industrial Management \& Data Systems, 114(6), 949-965. http://dx.doi.org/10.1108/IMDS-03-2014-0085.

Thomé, A. M. T., Scavarda, L. F., \& Scavarda, A. J. (2016). Conducting systematic literature review in operations management. Production Planning and Control, 27(5), 1-13. http://dx.doi.org/10.1080/09537287.2015.1129464.

Thomé, A. M. T., Scavarda, L. F., Fernandez, N. S., \& Scavarda, A. J. (2012). Sales and operations planning: a research synthesis. International Journal of Production Economics. http://dx.doi.org/10.1016/j.ijpe.2011.11.027.

Thun, J.-H., \& Hoenig, D. (2011). An empirical analysis of supply chain risk management in the German automotive industry. International Journal of Production Economics, 131(1), 242249. http://dx.doi.org/10.1016/j.ijpe.2009.10.010.

Torraco, R. J. (2005). Writing integrative literature reviews: guidelines and examples. Human Resource Development Review, 4(3), 356-367. http://dx.doi.org/10.1177/1534484305278283.

Tranfield, D., Denyer, D., \& Smart, P. (2003). Towards a methodology for developing evidenceinformed management knowledge by means of systematic review. British Journal of Management, 14(3), 207-222. http://dx.doi.org/10.1111/1467-8551.00375. 
Trkman, P., \& McCormack, K. (2009). Supply chain risk in turbulent environments: A conceptual model for managing supply chain network risk. International Journal of Production Economics, 119(2), 247-258. http://dx.doi.org/10.1016/j.jpe.2009.03.002.

Tummala, R., \& Schoenherr, T. (2011). Assessing and managing risks using the Supply Chain Risk Management Process (SCRMP). Supply Chain Management, 16(6), 474-483. http://dx.doi.org/10.1108/13598541111171165.

Tuncel, G., \& Alpan, G. (2010). Risk assessment and management for supply chain networks: A case study. Computers in Industry, 61(3), 250-259. http://dx.doi.org/10.1016/j.compind.2009.09.008.

Venkatesh, V. G., Rathi, S., \& Patwa, S. (2015). Analysis on supply chain risks in Indian apparel retail chains and proposal of risk prioritization model using Interpretive structural modeling. Journal of Retailing and Consumer Services, 26, 153-167. http://dx.doi.org/10.1016/j.jretconser.2015.06.001.

Vilko, J. P. P., \& Hallikas, J. M. (2011). Risk assessment in multimodal supply chains. International Journal of Production Economics. http://dx.doi.org/10.1016/j.ijpe.2011.09.010.

Wagner, S. M., \& Bode, C. (2008). An empirical examination of supply chain performance along several dimensions of risk. Journal of Business Logistics, 29(1), 307-325. http://dx.doi.org/10.1002/j.2158-1592.2008.tb00081.x.

Wei, H., Dong, M., \& Sun, S. (2010). Inoperability input-output modeling (IIM) of disruptions to supply chain networks. Systems Engineering, 13(4), 324-339.

Wu, D., \& Olson, D. (2008). Supply chain risk, simulation, and vendor selection. International Journal of Production Economics, 114(2), 646-655. http://dx.doi.org/10.1016/j.ijpe.2008.02.013.

Wu, P., Mao, C., Wang, J., Song, Y., \& Wang, X. (2016). A decade review of the credits obtained by LEED v2.2 certified green building projects. Building and Environment, 102, 167-178. http://dx.doi.org/10.1016/j.buildenv.2016.03.026.

$\mathrm{Wu}, \mathrm{T}$., Blackhurst, J., \& Chidambaram, V. (2006). A model for inbound supply risk analysis. Computers in Industry, 57(4), 350-365. http://dx.doi.org/10.1016/j.compind.2005.11.001.

You, F., Wassick, J. M., \& Grossmann, I. E. (2009). Risk management for a global supply chain planning under uncertainty: models and algorithms. AIChE Journal. American Institute of Chemical Engineers, 55(4), 931-946. http://dx.doi.org/10.1002/aic.11721. 